\title{
Compressive and Flexural Strengths of Cement Stabilized Earth Bricks Reinforced with Treated and Untreated Pineapple Leaves Fibres
}

\author{
Nounagnon A. Vodounon ${ }^{*}$, Christopher Kanali2, John Mwero ${ }^{3}$ \\ ${ }^{1}$ Department of Civil and Construction Engineering, Institute for Basic Sciences Technology and \\ Innovation, Pan African University, Nairobi, Kenya \\ ${ }^{2}$ Department of Agricultural and Biosystems Engineering, Jomo Kenyatta University of Agriculture and \\ Technology, Nairobi, Kenya \\ ${ }^{3}$ Department of Civil and Construction Engineering, University of Nairobi, Nairobi, Kenya \\ Email: *nounagnonvodounon726@gmail.com
}

How to cite this paper: Vodounon, N.A., Kanali, C. and Mwero, J. (2018) Compressive and Flexural Strengths of Cement Stabilized Earth Bricks Reinforced with Treated and Untreated Pineapple Leaves Fibres. Open Journal of Composite Materials, 8, 145-160.

https://doi.org/10.4236/ojcm.2018.84012

Received: August 27, 2018

Accepted: October 27, 2018

Published: October 30, 2018

Copyright $\odot 2018$ by authors and Scientific Research Publishing Inc. This work is licensed under the Creative Commons Attribution International License (CC BY 4.0).

http://creativecommons.org/licenses/by/4.0/

\section{(c) () Open Access}

\begin{abstract}
This study compares the effect of treated pineapple leaves fibres (T-PALF) with sodium hydroxide solution and untreated fibres (N-PALF) on the compressive and flexural strength of earth bricks stabilized with 3\% and 5\% cement. The fibre content ranged from $0 \%$ to $5 \%$ in steps of $1 \%$ by weight. The compressive strength tests were made at 7, 14, 21 and 28 days of curing; the flexural strength test were conducted at 28 th day only. The results show that the T-PALF had a higher compressive strength when comparing to the N-PALF. The highest compressive strength of the bricks was obtained at 28 days of curing. The compressive strength at 28 days of stabilized brick at $3 \%$ and $5 \%$ of cement reinforced with T-PALF were 4.01 and $4.81 \mathrm{MPa}$, respectively, while the one reinforced with N-PALF was 3.19 and 4.63 MPa, respectively. The results further show that the highest flexural strength of both stabilized bricks at $3 \%$ and $5 \%$ of cement reinforced with T-PALF and N-PALF was obtained with the bricks stabilized with $5 \%$ of cement reinforced with T-PALF. This results show that bricks stabilized with $5 \%$ cement and reinforced with $3 \%$ of treated fibres content are good for construction of load bearing walls. It was observed; a significant improvement of the reinforced blocks under flexure than under compression.
\end{abstract}

\section{Keywords}

Compressed Stabilized Bricks, Treated Pineapple Leaf Fibres, Laterite Bricks, Compressive Strength, Flexural Strength and Reinforced 


\section{Introduction}

Nowadays there is a growing attention in the development of research on natural fibre reinforced composites or bio-composites, in widespread applications, including automotive, construction and aerospace [1] [2]. Fibre reinforced composites can be used for a lot of civil engineering applications including roofing tiles (Agopyan et al., 2005), corrugated slabs (Paramasivam et al., 1984), simple slab panels (Ramakrishna and Sundararajan, 2005), boards (Li et al., 2007; Asasutjarita et al., 2007; Aggarwal, 1992) and mortar (Toledo Filho et al., 2005) [3].

Reinforced soils are solid composites which consist of gathering two or more different structures in which their identities are preserved. The advantages of newly produced composites are higher specific strength, stiffness, and lower thermal conductivity (Kazemian et al., 2010) [4]. Reinforced soil techniques are exemplified by bricks made from clay reinforced with straw by the Egyptians in the third millennium BC (Mathews and Rawling, 1994). Laterite soil is among the most available construction materials in the world.

Pineapple leave fibre has been used for long time to reinforce composite and the results were significant; but due to lack of standards it has not yet been used properly in civil engineering field. Recently, some research started going in this direction of using pineapple to reinforce concrete [1]. Short and fine pineapple leaf fiber (PALF) was used to reinforce Nitrile rubber composite and it was found that the stress-strain curves of the composites were greatly modified [2]; many others researches have also been made in polymer composite and there was a significant improvement; seen all these advantages of Pineapple leaves fibre, it is time to try such fibre in soil block reinforcement. Hence this study was made.

Much effort has gone into improving the mechanical properties of laterites to enhance their performance in order to meet the demand for their wider applications [5]. Natural fibers have been used for centuries in several processes such as clothing and in buildings industry (Mohanty et al., 2005). Natural fibres from pineapple leaves are a good option to study because of their high tensile strength and high cellulose content (Kalia \& Kaith, 2011) [5]. The use of fibre-reinforcement in construction materials can enhance structural strength and toughness, and this can reduce cracking and shrinkage [6]. This study assessed the mechanical properties of reinforced bricks with pineapple leaves fibres (PALF).

\section{Material Acquisition and Experimental Set-Up}

\subsection{Material Acquisition}

The study was conducted at Jomo Kenyatta University of Agriculture and Technology (JKUAT) from February to June 2018. JKUAT is located in Juja township, $10 \mathrm{~km}$ West of Thika town and $45 \mathrm{~km}$ East of Nairobi, Kenya. The latitude, longitude and altitude of the location are $1.18^{\circ} \mathrm{S}, 37^{\circ} \mathrm{E}$ and $1460 \mathrm{~m}$ above sea level, respectively. Laterite soil and sand used for the study were procured from Juja and Nyeri, respectively. The soil was kept under polyetilene cover to 
ensure that it was neither too dry (by sun dry) nor too wet (by rain). In addition, Pozzolanic cement CEM IV/B 32.5R used in the study was formulated in accordance to the KS EAS 18-1:2001, which is adopted from the EN 197-1 European Standards. Finally, PALF which were the main material to be used for reinforcing the bricks were obtained from Hand Conifer Company Ltd, Mumbai, India. The fibres were extracted from the leaves by using mechanical extractor machine.

\subsection{Data Collection Procedure and Analysis}

\subsubsection{Determining the Physical and Chemical Properties of the Soil}

The physical properties for the soil that were examined included moisture content, maximum dry density, Atterberg limits and soil size particle distribution. The moisture content was determined according to BS 1377:1990. Dry density, Atterberg limits and the size distribution were analysed at JKUAT, as per to BS 1377-2:1990 [3]. On the other hand, the chemical composition of the soil assessed proportions of silicon oxide $\left(\mathrm{SiO}_{2}\right)$, aluminium oxide $\left(\mathrm{Al}_{2} \mathrm{O}_{3}\right)$, calcium oxide $(\mathrm{CaO})$, magnesium oxide $(\mathrm{MgO})$, sodium oxide $\left(\mathrm{Na}_{2} \mathrm{O}\right)$, potassium oxide $\left(\mathrm{K}_{2} \mathrm{O}\right)$, titanium oxide $(\mathrm{TiO})$, manganese oxide $(\mathrm{MnO})$, ferrous oxide $\left(\mathrm{Fe}_{2} \mathrm{O}_{3}\right)$ and loss on ignition (LOI) which represents the mass of moisture and volatile material present in a sample. The volatile materials lost usually consist of "combined water" and carbon dioxide from carbonates. These properties were analysed according to BS 1377-3:1990 [4] at the laboratories of the Ministry of Mining and Petroleum, Government of Kenya.

\subsubsection{Evaluating the Chemical Properties and Tensile Strength of Pineapple Leaf Fibres}

In order to assess the chemical properties and tensile strength of the PALF it was necessary to treat the fibres in a $4 \%$ of sodium hydroxide $(\mathrm{NaOH})$ solution over various durations. The $\mathrm{NaOH}$ treatment is one of the best treatment used for natural fibres. It helps to increase the fibre surface roughness by chemically modifying and cleaning the fibre surface [5]. The $4 \% \mathrm{NaOH}$ solution was prepared by dissolving $80 \mathrm{~g}$ of $\mathrm{NaOH}$ in $2000 \mathrm{~cm}^{3}$ of distilled water, because according to J. P. Siregar et al. PALF treated in $\mathrm{NaOH}$ concentration of $4 \%$ showed the highest mechanical properties value (Siregar, Sapuan, Rahman, \& Zaman, 2010). Thereafter, four (4) samples of PALF, each weighing $70 \mathrm{~g}$, were immersed in the $\mathrm{NaOH}$ solution for 30,60,120 and 180 minutes. The control treatment involved no immersion of the fibres in the $\mathrm{NaOH}$ solution, and this represented zero (0) minutes duration of immersion. The chemical properties (i.e., proportions of cellulose, hemicellulose and lignin) of the treated four (4) fibre samples were determined based the procedure described by Direct method of cellulose, hemicelluloses and lignin (Moubasher et al., 1982) [6]. Tensile strengths for all the samples were analysed using HOUNSFIED TENSOMETER machine as per the ASTM D 3822-07 standard. Scanning electron microscopy (SEM) analysis was carried out at the Botswana Institute for Technology Research and Innovation (BITRI), Botswana, with $2.0 \mathrm{~K} \times$ magnification. The aim of the SEM test was to 
show the effect of $\mathrm{NaOH}$ solution treatment on PALF at optimum tensile strength.

\subsubsection{Determining the Mechanical Properties of Cement Stabilized Bricks Reinforced with Pineapple Leaf Fibres}

1) Mix Design and Pineapple Leaf Fibre Reinforced Brick Preparation

The different specimens were prepared as follows. First, Portland cement, sand and laterite soil were mixed in proportions of $3 \%, 27 \%$ and $70 \%$ by mass, respectively, and water was added to form a paste of acceptable range of moisture content, where simple drop test in done according to the New Zealand Standard 4298 (1998) [7]. This formed the first specimen. Another specimen comprising a mixture of 5\%, $25 \%$ and $70 \%$ of Portland cement, sand and laterite soil, respectively, was prepared in similar manner. For both specimen, T-PALF and N-PALF were added in proportions of $0 \%$ to $5 \%$ in steps of $1 \%$ by mass of cement. The length of fibres used in this study was on average $30 \mathrm{~mm}$ since it necessary the fibres be short and straight to enable a quick dispersal without clinging [8]. Hand shovel mixing was used to ensure that there is a good dispersion of the fibres in the cement to prevent balling up. Laterite soil and sand were added after mixing cement with the fibres. The mixing process took 10 minutes to ensure an even dispersion of all the materials.

After mixing, the materials were poured into a manual stabilized soil block machine to make the bricks. The machine had a hydraulic pressure gauge and was set at a constant pressure of $10 \mathrm{MPa}$. The bricks were then wrapped with a plastic film to avoid rapid drying and stored under a sheltered area for 7 days. Thereafter, they were stored in the open air for 21 days for curing.

\section{2) Determining the Mechanical Properties of the Bricks}

Compressive strength of the bricks stabilized with $3 \%$ and $5 \%$ of cement and reinforced with N-PALF and T-PALF at $0 \%$ to $5 \%$ was determined. Servo-plus evolution testing machine was used for the test. Initially, the compressive strength was determined at 7, 14, 21 and 28 days of curing, and it was conducted in accordance to BS EN 772-1 (2011). Loading was done at a rate of $0.05 \mathrm{~N} / \mathrm{mm}^{2} \cdot \mathrm{s}^{-1}$ until the brick failed and the maximum compressive stress recorded. On the other hand, the flexural strength was conducted according to ASTM C67-07 [9]. Three-point loading system was utilized with one centre point force application on a simply supported brick of dimension $290 \mathrm{~mm} \times 140$ $\mathrm{mm} \times 120 \mathrm{~mm}$. The bricks were centred between the two supports of the hydraulic press under the loading so that the span to depth ratio was approximately 2.07 , as shown in Figure 1. Then the loading was set at a steady rate of $5 \mathrm{~N} \cdot \mathrm{s}^{-1}$.

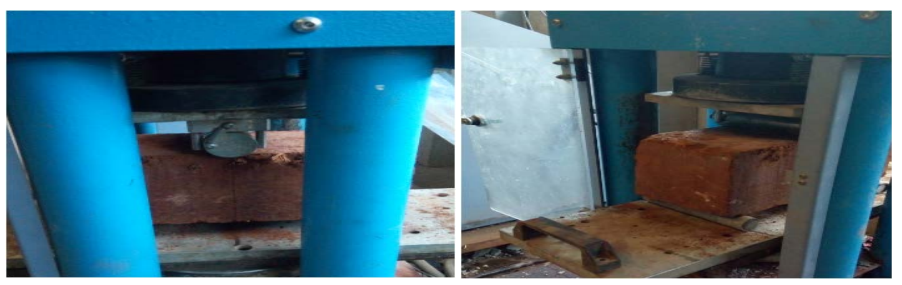

Figure 1. Flexural strength test set-up. 


\section{Results and Discussion}

\subsection{Physical and Chemical Properties of the Soil}

The results of the physical properties of the soil used in this study are shown in Table 1. The results show that the sand and clay proportions are each equal to $20 \%$. This amount of clay is high for making good soil bricks according to [10]. In order to reduce the clay dominance in the bricks some sand was added, be cause high clay content leads to excessive drying shrinkage, and it lessens durability and compressive strength [10]. The average sand particle size was below $5 \mathrm{~mm}$, while the recorded soil moisture content was 2.36\% (dry basis).

Table 1. Physical properties of the soils.

\begin{tabular}{cc}
\hline Properties & Values \\
\hline Proctor test: & 31.1 \\
Optimum moisture content (\%) & 1351 \\
Maximum dry density $\left(\mathrm{kg} / \mathrm{m}^{3}\right)$ & \\
Atterberg limits: & 54 \\
Liquid limit, wL (\%) & 28 \\
Plastic limit, wp (\%) & 27 \\
Plasticity index & $\mathrm{CH}$ \\
Soil classification (USCS): & \\
Particle size distribution: & 2 \\
Gravel $(20-2 \mathrm{~mm})(\%)$ & 20 \\
Sand $(2-0.06 \mathrm{~mm})(\%)$ & 58 \\
Silt $(0.06$ - $0.002 \mathrm{~mm})(\%)$ & 20 \\
Clay $(<0.002 \mathrm{~mm})(\%)$ & 7.31 \\
pH: & \\
Value & \\
\hline
\end{tabular}

Table 2 shows the chemical composition of the soil, and it can be seen that the Silica Sesquioxides ratio $\left(\mathrm{SiO}_{2} /\left[\mathrm{Al}_{2} \mathrm{O}_{3}+\mathrm{Fe}_{2} \mathrm{O}_{3}\right]\right)$ of the soil is equal to 1.5 . This value is between 1.33 and 2.0 implying that the soil was indeed laterite soil, according to previous study [11]. Laterite soil is the most suitable soil for making bricks because of its properties are not significantly affected by changes in its moisture. All these properties make the soil to be suitable for making bricks.

The particle size distribution of the soil corresponds to result of both dry sieving and hydrometer test (see Figure 2). It is observed that $58 \%$ of the soil passed through $0.06 \mathrm{~mm}$ sieve, indicating that the soil has a fine texture, according to ASTM. The fine texture of the soil confirms its high clay and silt content. Furthermore, it confirms why the soil has high liquid limit and plasticity index values which are not suitable for making soil bricks since this leads to exces- 
sive drying shrinkage, and low durability and compressive strength. In the way to reduce liquid limit and plasticity index, $25 \%$ of sand was added in the soil.

Table 2. Chemical composition of the soil.

\begin{tabular}{cc}
\hline Chemical composition & Proportion (\%) \\
\hline $\mathrm{SiO}_{2}$ & 51.31 \\
$\mathrm{Al}_{2} \mathrm{O}_{3}$ & 22.26 \\
$\mathrm{CaO}$ & 1.33 \\
$\mathrm{MgO}$ & 0.06 \\
$\mathrm{Na}_{2} \mathrm{O}$ & 2.5 \\
$\mathrm{~K}_{2} \mathrm{O}$ & 1.7 \\
$\mathrm{TiO}^{\mathrm{NOO}}$ & 1.25 \\
$\mathrm{MnO}$ & 0.34 \\
$\mathrm{Fe}_{2} \mathrm{O}_{3}$ & 8.00 \\
$\mathrm{LOI}$ & 10.00 \\
\hline
\end{tabular}

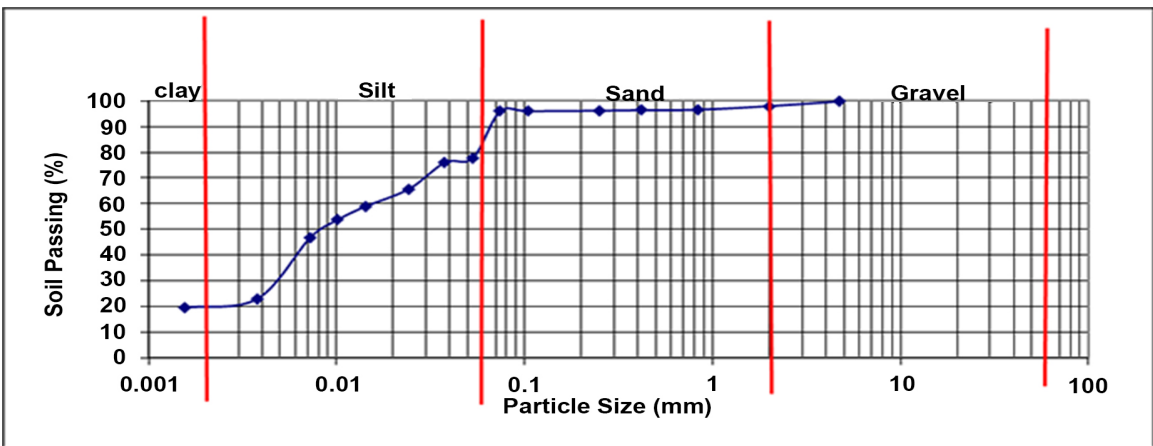

Figure 2. Particle size distribution of the soil used for the study.

\subsection{Chemical Properties and Tensile Strength of Pineapple Leave Fibres}

The results for the chemical properties of the PALF are presented in Table 3 and they show that cellulose, hemicellulose and lignin decreased with increase in duration of treatment of the fibres with $\mathrm{NaOH}$ solution. This was due to the fact that the $\mathrm{NaOH}$ solution cleaned impurities from the fibres. The small quantity of lignin present allowed the fibres and the soil matrix to have sufficient adherence, as reported by Asim et al., 2015 [12].

Figure 3 shows the relationship between tensile strength and duration of treatment of the fibres with $\mathrm{NaOH}$ solution. It can be seen that the tensile strength increased with the duration of treatment up to an optimum value of $766.9 \mathrm{MPa}$ after 106.8 minutes, thereafter the strength decreased. A polynomial relation exists between tensile strength and duration of treatment with a strong correlation as the coefficient of determination $\left(\mathrm{R}^{2}=0.86\right)$ is high. The tensile strength of the fibres increased after the treatment because non-cellulosic mate- 
rials were removed from them [12]. On the other hand, the fibre strength started decreasing after 106.8 minutes of treatment of the fibres as the $\mathrm{NaOH}$ solution started removing impurities (i.e., destroying the cellulose) from them. The 106.8 minutes of treatment seems to be the best duration for treating PALF with $4 \%$ of $\mathrm{NaOH}$ solution in order to obtain the highest tensile strength. This is confirmed by J. P. Siregar et al. 2010 [13]. It is important to care about the time of treatment of all natural fibres, since this study confirms the works of others researchers on the treatment of natural fibre, especially with $\mathrm{NaOH}$ solution.

The main purpose of the above treatment was to use the fibres with the highest tensile strength for soil reinforcement for making bricks. However, in this study the experimental value of $751.95 \mathrm{MPa}$ corresponding to one (1) hour duration of treatment were selected. The numerical value was determined later after using the experimental value. Nevertheless, the difference between the experimental and numerical values is insignificant as the former is was just 1.99\% less than the later. It is then recommended that future studies should establish the feasibility of using fibres with the numerically established tensile strength value.

Table 3. Chemical composition of pineapple leave fibres for $4 \%$ treatment of $\mathrm{NaOH}$ solution.

\begin{tabular}{cccc}
\hline \multirow{2}{*}{$\begin{array}{c}\text { Duration of } \\
\text { treatment }(\mathrm{min})\end{array}$} & \multicolumn{3}{c}{ Chemical composition (\%) } \\
\cline { 2 - 4 } & Cellulose & Hemi-cellulose & Lignin \\
\hline $0^{*}$ & 78.676 & 70.775 & 10.321 \\
30 & 75.76 & 68.443 & 9.300 \\
60 & 74.87 & 67.551 & 9.26 \\
120 & 74.23 & 67.48 & 9.15 \\
180 & 74.005 & 66.812 & 9.055 \\
\hline
\end{tabular}

${ }^{*}$ Corresponds to N-PALF while the rest (30-180) correspond to T-PALF.

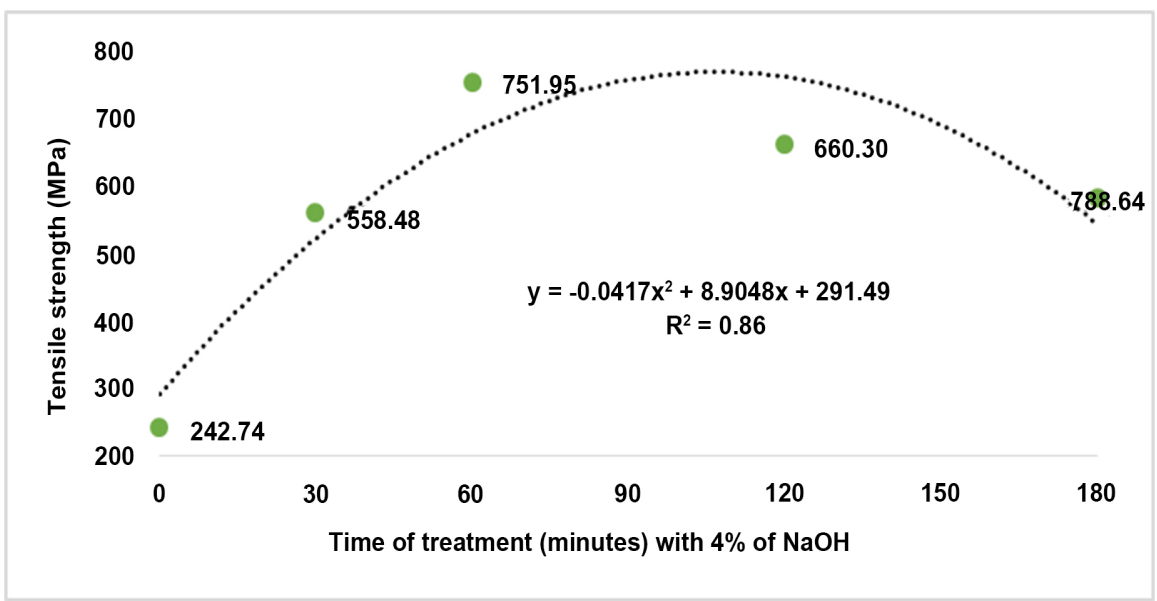

Figure 3. Relation between pineapple leaf fibre tensile strength and duration of their treatment in $4 \% \mathrm{NaOH}$ solution. 
The Scanning Electron Microscopy (SEM) results for the treated after (1) hour duration of treatment in $\mathrm{NaOH}$ solution and untreated pineapple leaves fibre are presented in Figure 4. These two SEM photos were selected because the fibres were used to reinforce the laterite soil. It can be seen that T-PALF, Figure 4(a) has a smooth surface compared to N-PALF (Figure 4(b)) because the $\mathrm{NaOH}$ treatment has removed the cellulose impurities from the fibres, and this made them to become more flexible and increase its adhesion with the soil matrix.

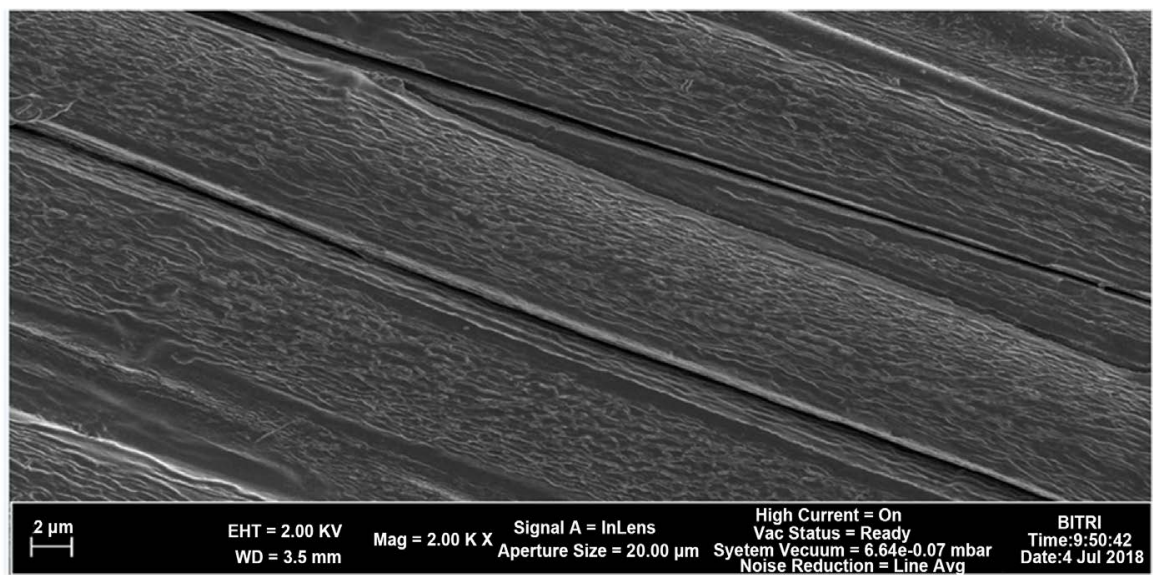

(a)

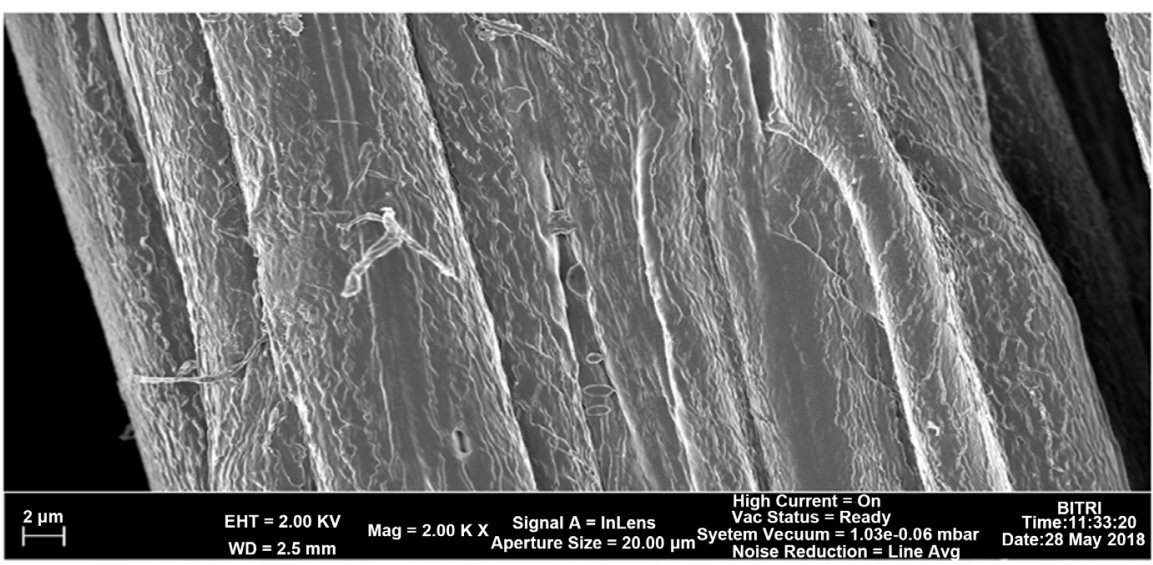

(b)

Figure 4. Scanning Microscopy Electron result for untreated and treated palm leaf fibres. (a) Treated PALF (T-PALF) for one hour in $\mathrm{NaOH}$ solution; (b) Untreated PALF (N-PALF).

\subsection{Compressive Strength of Cement Stabilized Bricks Reinforced with Pineapple Leaf Fibres}

Compressive strength tests of four sets of bricks were made; the first and second sets were for bricks stabilized with $3 \%$ of cement reinforced with N-PALF and T-PALF, respectively, while the third and fourth sets were for bricks stabilized with $5 \%$ of cement reinforced N-PALF and T-PALF, respectively.

Figure 5 presents the relationship between the compressive strength of bricks stabilized with $3 \%$ cement and various proportions of N-PALF. It is observed 
that the compressive strength of the reinforced bricks with N-PALF increased with increase of fibre content up to $3 \%$, thereafter it decreased. According to the ACI Material, Journal Committee all the compressive strengths of the bricks reinforced with $0 \%$ to $5 \%$ of fibre content at 21 and 28 days of curing met the minimum threshold of 1.72 MPa. However, the highest value of 3.19 MPa corresponded to the $3 \%$ fibre content value at 28 days of curing; hence the focus was on this fibre content value which is also above the minimum threshold of 2.068 MPa recommended by ASTM International E2392/E2392M-10e1 (2010). According to Tanzania Standard 283:1986 (TZS 283:1986) the minimum of strength of 3.5 MPa was recommended for load bearing walls; hence these bricks cannot be used for bearing wall.

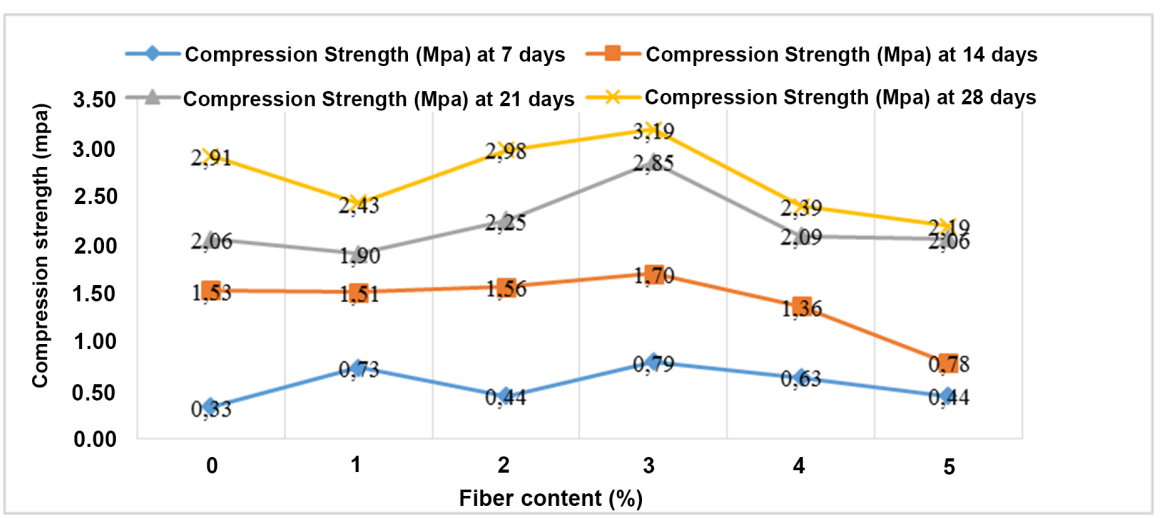

Figure 5. Compressive strength of bricks stabilized with $3 \%$ of cement and reinforced with various proportions of N-PALF.

The relationship between the compressive strength of bricks stabilized with $3 \%$ cement and various proportions of T-PALF are shown in Figure 6. As in Figure 5, it is can be seen that the compressive strength of the reinforced bricks with T-PALF increased with increase of fibre content up to $3 \%$, thereafter it decreased. According to the ACI Material, Journal Committee all the compressive strengths of the bricks reinforced with $0 \%$ to $5 \%$ of fibre content at 21 and 28 days of curing met the minimum threshold of $1.72 \mathrm{MPa}$. Similarly, the bricks with $2 \%$ to $4 \%$ of fibre content at 14 days of curing met this minimum threshold. The results also show that the compressive strengths of 3.81 and 4.01 MPa corresponded to $3 \%$ fibre content at 21 and 28 days of curing, respectively, hence, according to Tanzania Standard 283:1986 (TZS 283:1986) this mixture can be used for load bearing walls.

Figure 7 shows the relation between the compressive strength of bricks stabilized with $5 \%$ cement and various proportions of N-PALF. As above the compressive strength increased with increase of fibre content up to $3 \%$, thereafter it decreased. All the compressive strengths of the bricks reinforced with $0 \%$ to $5 \%$ of fibre content at 14 to 28 days of curing met the minimum threshold according to the ACI Material, Journal Committee. According to ASTM International E2392/E2392M-10e1 (2010) at 14 days of curing the bricks with $1 \%$ to $5 \%$ of fi- 
bre content met the minimum strength. The results also show that the compressive strengths of $3.58 \mathrm{MPa}$ corresponding to $2 \%$ fibre content at 28 days of curing while 4.41 and $4.63 \mathrm{MPa}$ corresponding to $3 \%$ fibre content at 21 and 28 days of curing, respectively, can also be used for load bearing walls.

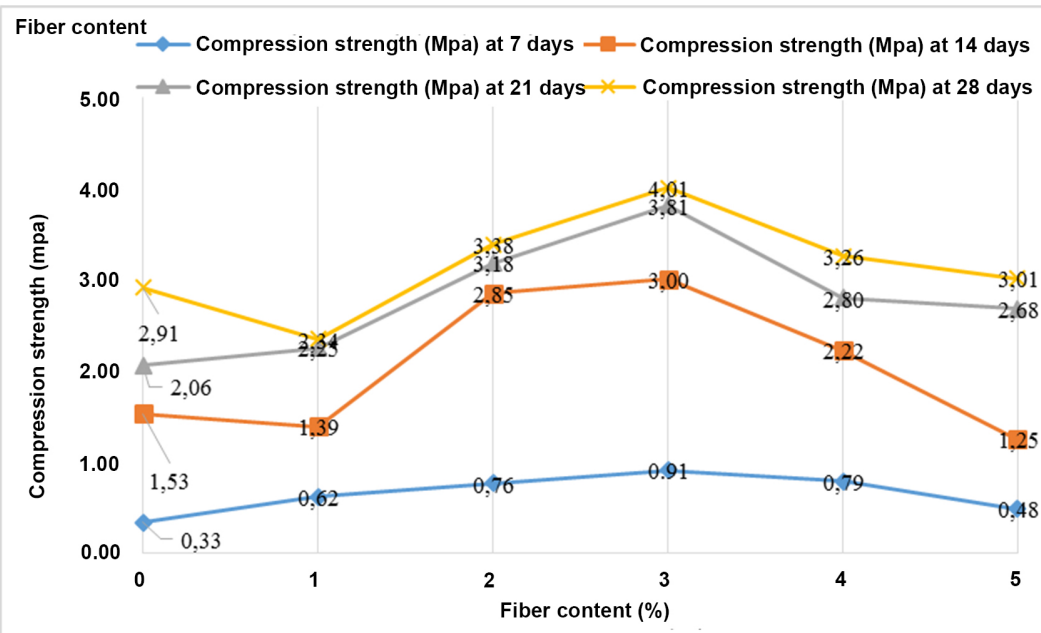

Figure 6. Compressive strength of bricks stabilized with $3 \%$ of cement and reinforced with various proportions of T-PALF.

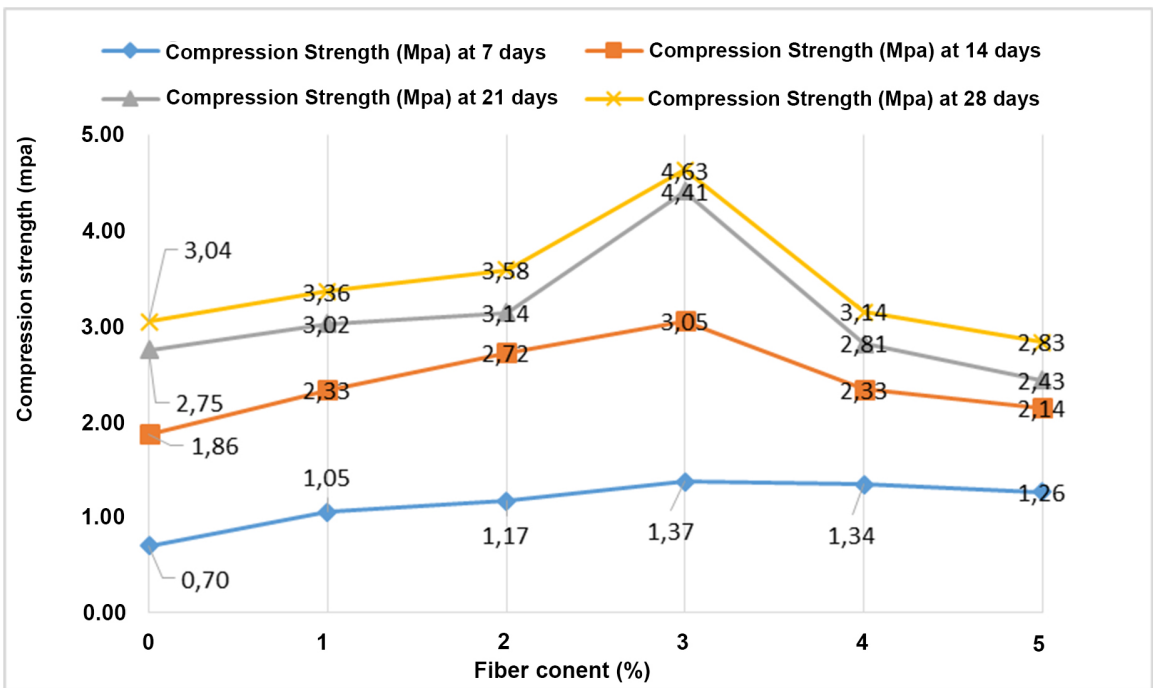

Figure 7. Compressive strength of bricks stabilized with $5 \%$ of cement and reinforced with various proportions of N-PALF.

The results for relationship between the compressive strength of bricks stabilized with $5 \%$ cement and various proportions of T-PALF are presented in Figure 8. As above the compressive strength increased with increase of fibre content up to $3 \%$, thereafter it decreased. All the compressive strengths of the bricks reinforced with $0 \%$ to $5 \%$ of fibre content at 14 to 28 days of curing met the minimum threshold according to the ACI Material, Journal Committee. It is also observed that at 7 days of curing the bricks with $3 \%$ of fibre content met mini- 
mum threshold. According to ASTM International E2392/E2392M-10e1 (2010) at 14 days of curing the bricks with $1 \%$ to $4 \%$ of fibre content met the minimum strength, in the similar way at 21 and 28 days of curing all the bricks met the minimum strength required by this standard. The results also show that load bearing walls can also be made from bricks with $1 \%$ to $3 \%$ fibre content at 21 and 28 days of curing, and $3 \%$ fibre content and 14 days of curing as the compressive strengths obtained ranged from 3.50 to $4.81 \mathrm{MPa}$, according to Tanzania Standard 283:1986 (TZS 283:1986).

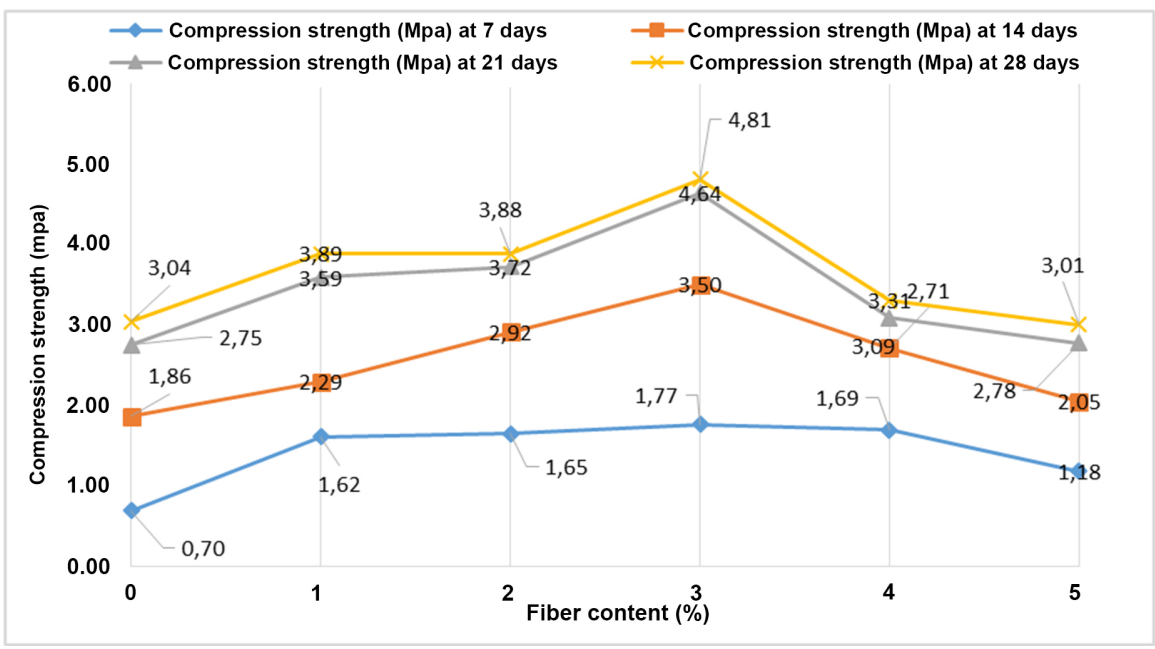

Figure 8. Compressive strength of bricks stabilized with $5 \%$ of cement and reinforced with various proportions of T-PALF.

\subsection{Brief Discussion of All above Results on Compressive Strength}

Based on the above results, the compressive strength increased with fibre content because the fibres within the bricks supported the applied load up to the $3 \%$ content level. However, above this level the compressive strength decreased because the amount of fibre in the mixture was high and instead of reinforcing the bricks the fibre started sticking together, forming waste matrix within the bricks making the bricks to loose strength. Similar observation was made by Humphrey Danso et al. [8] and Sallehan Ismail et al. 2011 [14]. At the normal percentage of fibre within soil particle, the fibres are able to carry the compressive strength load applied to bricks.

The results also show that the bricks reinforced with T-PALF performed better than the N-PALF. This is due to the fact that $\mathrm{NaOH}$ solution treatment improved the tensile strength of the fibres and this improvement allowed the treated fibres to boost the strength of the bricks as compared to those reinforced with non-treated fibres. Similar observations were made by L. Uma Devi et al., 1996, and a significant improvement in the tensile strength was reported for polyester composites reinforced with treated PALF [15]. The increase in strength with T-PALF is due to the fact that there is high adhesion between the soil par- 
ticles and the treated fibres as compared to non-treated ones.

Finally, the results show that the performance of reinforced bricks stabilised with $5 \%$ of cement was higher than that with $3 \%$ of cement. Many other researchers (references) have found that $5 \%$ to $10 \%$ of cement is the best range to stabilize soil bricks, which supports the findings of this study. It is also important to mention that from this study with $5 \%$ of cement the fibre content is more suitable than with $3 \%$ since the fibres were added in terms of percentage weight of cement. The Standard Deviation (STDEV) of the compressive strength of the brick at 28 days are presented in Table 4 , the results of this table shown that the STDEV of reinforced brick are higher than the ones of unreinforced bricks.

Table 4. Standard Deviation of the compressive strength of the brick at 28 days.

\begin{tabular}{ccccccc}
\hline \multirow{2}{*}{ Fibre content (\%) } & \multicolumn{7}{c}{ Compressive strength of speciments at 28 days of curing } & \multirow{2}{*}{ Mean } & STDEV \\
\cline { 2 - 5 } & 3N-PALF & 3T-PALF & 5N-PALF & 5T-PALF & & \\
\hline 0 & 2.91 & 2.91 & 3.04 & 3.04 & 2.975 & 0.06 \\
1 & 2.43 & 2.34 & 3.36 & 3.89 & 3.005 & 0.65 \\
2 & 2.98 & 3.38 & 3.58 & 3.88 & 3.455 & 0.33 \\
3 & 3.19 & 4.01 & 4.63 & 4.81 & 4.16 & 0.63 \\
4 & 2.39 & 3.26 & 3.14 & 3.31 & 3.025 & 0.37 \\
5 & 2.19 & 2.92 & 2.83 & 3.01 & 2.7375 & 0.32 \\
\hline
\end{tabular}

\subsection{Failure Mode of the Bricks under Compression}

Figure 9 shows the failure mode of the bricks under compression. It can be seen that there was a brittle failure for the unreinforced brick (Figure 9(a)) while with the reinforced one (Figure 9(b)), it appears that there was shearing and a crack was formed. For the reinforced one, the fibres made the bricks to become more ductile, flexible and elastic making the bricks to resist brittle failure. As seen from Figure 9(b) the base of the brick widened under compression. This was due to the fact that, under compression the fibres held together the soil particles against brittle failure and they enabled the brick with stand cracking. The cracks appeared because the fibres reached failure point letting the soil matrix to foil.

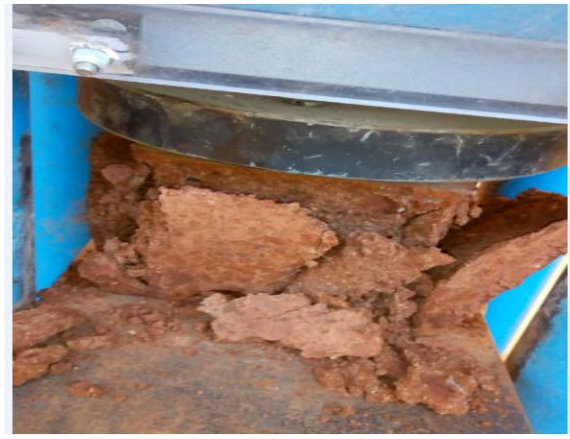

(a)

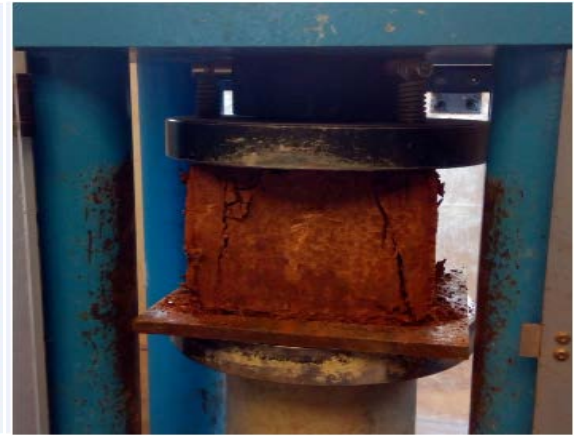

(b)

Figure 9. Compression test on the blocks. (a) Unreinforced brick; (b) Reinforced brick. 


\subsection{Flexural Strength of Cement Stabilized Bricks Reinforced with Pineapple Leaf Fibres}

The flexural strength results are shown in Figure 10, and it can be seen that the flexural strength of the bricks has increased with increase of fibre content up to $3 \%$ of fibre content, afterward it decreased as observed with previous compressive strength of the blocks in Section 3.3. A similar observation has been made with the flexural strength of pressed adobe bricks reinforced with Hibiscus Cannabinus fibres [16].

The flexural strength of bricks reinforced with T-PALF has shown a higher result as compare to those reinforced with N-PALF. At the optimum fibre content (3\% of PALF) the flexural strength of the stabilized bricks with $5 \%$ of cement were $0.64 \mathrm{MPa}$ and $0.92 \mathrm{MPa}$ respectively for bricks reinforced with N-PALF and T-PALF, while for the control brick it was $0.43 \mathrm{MPa}$; so there is increased of $48.84 \%$ and $113.95 \%$ respectively with N-PALF and T-PALF over the unreinforced bricks. In the same manner, at the optimum fibre content (3\% of PALF) the flexural strength of stabilized bricks with $3 \%$ of cement were 0.38 $\mathrm{MPa}$ and $0.49 \mathrm{MPa}$ respectively for bricks reinforced with N-PALF and T-PALF, while for the control brick was $0.26 \mathrm{MPa}$; so there is increased of $46.15 \%$ and $88.46 \%$ respectively with N-PALF and T-PALF over the unreinforced bricks. The T-PALF have more restricted crack tip propagation and blunt the crack tip than N-PALF and this led to increase the flexural strength of the bricks better with T-PALF than with N-PALF.

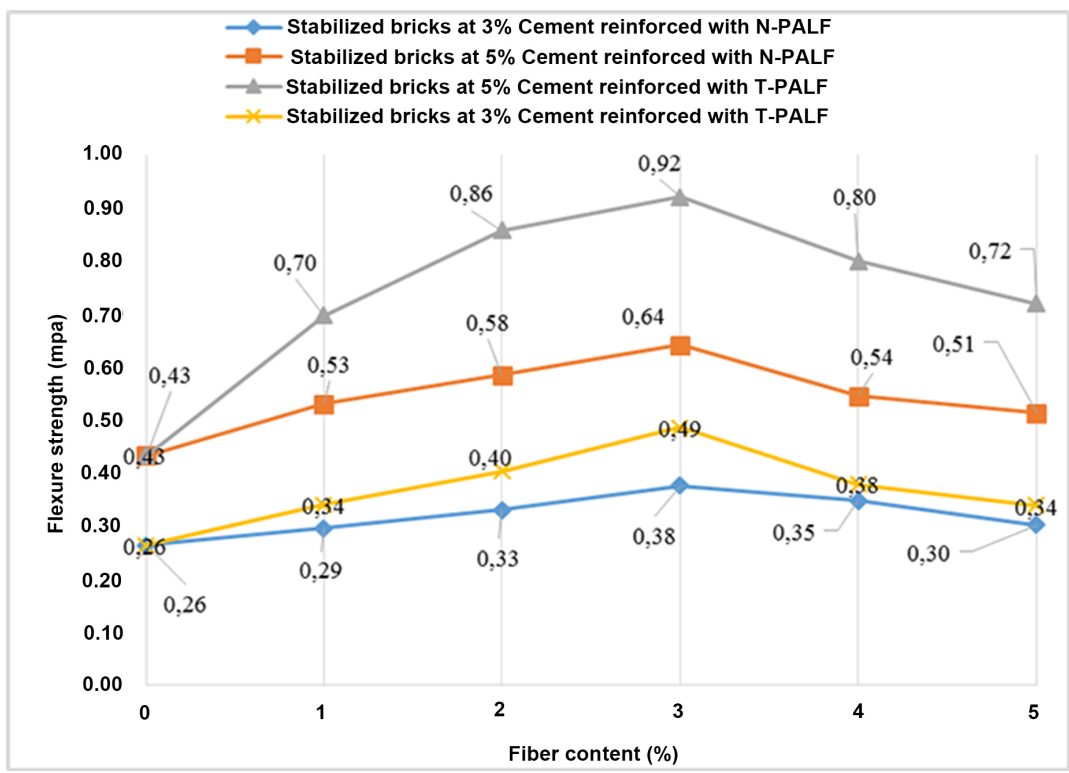

Figure 10. Flexure strength tests result of bricks after 28 days.

The T-PALF have increased the strength of the bricks in flexure more than in compression, this is showing that the fibre acted more in traction than in compression within the composite as the case with steel reinforcement in concrete beam. More again, the best fibres content in the bricks is with $5 \%$ of cement. 
Table 5 shows the percentage of increase of reinforced bricks with each percentage of fibres content comparing to unreinforced bricks. On the other hand, Figure 11, has shown the reinforced block doesn't have a brittle break while (plain) the unreinforced one does. This was because the fibres inside the block have increased their stress of resistance under bending.

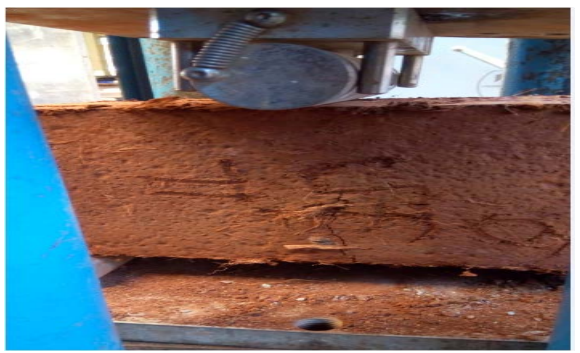

(a)

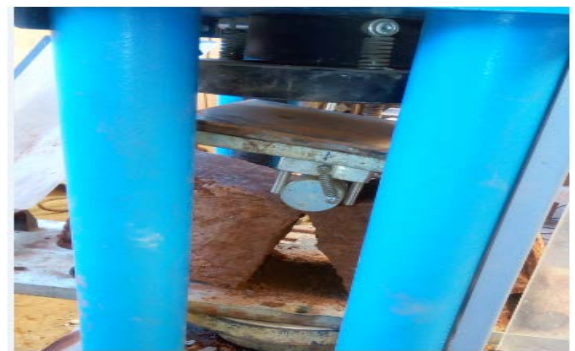

(b)

Figure 11. (a) Reinforced CEB flexural failure. (b) Plain CEB flexural failure.

Table 5. Percentage increase in flexural strength (3 N-PALF means: bricks stabilized with $3 \%$ cement and reinforced with N-PALF).

\begin{tabular}{ccccc}
\hline \multicolumn{5}{c}{ Percentage of Increase compare to unreinforced bricks } \\
\hline Fibres content (\%) & 3 N-PALF & 3 T-PALF & 5 N-PALF & 5 T-PALF \\
\hline 1 & 11.90 & 29.11 & 22.36 & 60.99 \\
2 & 24.94 & 52.91 & 34.93 & 98.15 \\
3 & 42.53 & 84.18 & 48.19 & 112.80 \\
4 & 31.65 & 43.54 & 25.83 & 84.66 \\
5 & 14.56 & 28.23 & 18.50 & 66.23 \\
\hline
\end{tabular}

\section{Conclusions}

This study investigated the compressive strength of bricks stabilized with $3 \%$ and $5 \%$ of cement and reinforced with non-treated and treated pineapple leaf fibre. The results show that:

1) The soil had a high content of both clay and sand (20\%) for making good bricks, and for that reason some sand was added to reduce the dominance of clay as this would lead to excessive drying shrinkage, and reduced durability and compressive strength. The soil is laterite as the Silica Sesquioxides ratio $\left(\mathrm{SiO}_{2} /\left[\mathrm{Al}_{2} \mathrm{O}_{3}+\mathrm{Fe}_{2} \mathrm{O}_{3}\right]\right)$ is equal to 1.5 .

2) The amount of cellulose, hemicellulose and lignin in the fibres decreased with increase in duration of treatment with sodium hydroxide solution. In addition, the treatment increased the tensile strength of the fibres up to an optimum of $766.9 \mathrm{MPa}$ after 106.8 minutes.

3) Compressive strength of the fibre reinforced bricks increased with increase in fibre content up to 3\%; thereafter it decreased. At 3\% cement stabilization, 3\% of treated fibres and 21 to 28 days of curing, the bricks attained enough compressive strength for construction of load bearing walls. However, better per- 
formance was obtained for $5 \%$ cement stabilized bricks at $3 \%$ fibre content. The bricks reinforced with sodium hydroxide treated fibres had higher compressive strength than non-treated fibres.

4) Flexural strength of the fibre reinforced bricks increased with increase in fibre content up to $3 \%$; thereafter it decreased. The treated fibres have significantly improved the flexural strength of the bricks comparing to compressive strength.

\section{Acknowledgements}

This research was supported/partially supported by The Pan African University Institute of Basic Sciences Technology and Innovation (PAUISTI) of Kenya. We thank Mr. GARUGU for assistance with Laboratory material. We would also like to show our gratitude to Prof. Gabriel Nyamwamu Magoma, Director of PAUISTI.

\section{Author's Contributions}

S.H.C. conceived the study, designed experiments and interpreted the results; M.T. developed analytical tools and wrote the paper; N.C. analyzed data and wrote the paper.

\section{Review Process}

This paper has been reviewed by 3 reviewers. 2 reviewers opted to be made public: FirstName1 LastName1, Affiliation1; FirstName2 LastName2, Affiliation2. The corresponding author is marked with *

\section{Previous Presentation}

Parts of this paper were published/made public before... (if it applies, provide reference to source and specify which part of the paper). See http://AAST.ProfScholz.de for more details on writing this title footnote. The lead of each line is colored with RGB: 49/132/155 (SCIRP Title Footnote).

\section{Conflicts of Interest}

The authors declare no conflicts of interest regarding the publication of this paper.

\section{References}

[1] de Aro, E.F., Hur, B., Fajardo, J.C. and Perez, M.A. (2012) Properties of Pineapple Leaf Fiber-Reinforced Concrete Beams. Mapúa Institute of Technology, Manila.

[2] Wisittanawat, U., Thanawan, S. and Amornsakchai, T. (2014) Mechanical Properties of Highly Aligned Short Pineapple Leaf Fiber Reinforced-Nitrile Rubber Composite: Effect of Fiber Content and Bonding Agent. Polymer Testing, 35, 20-27. https://doi.org/10.1016/j.polymertesting.2014.02.003

[3] BS (1990) Soils for Civil Engineering Purposes. Vol. 3, 1377-2: 1990.

[4] BS (1990) Methods of Test for Soils for Civil Engineering Purposes-Part 3: Chem- 
ical and Electro-Chemical Tests. 1377-3:1990.

[5] Ahad, N.A., Parimin, N., Mahmed, N. and Ibrahim, S.S. (2009) Effect of Chemical Treatment on the Surface of Natural Fiber. Journal of Liquid Chromatography \& Related Technologies, 6, 155-158.

[6] Alarmelumangai, K., Malathy, K., Brindha, D. and Vinodhini, S. (2012) Physico-Chemical Properties of Fibers from Banana Varieties after Scouring. Indian Journal of Fundamental and Applied Life Sciences, 2, 217-221.

[7] (1998) NZS 4298: Materials and Workmanship for Earth Buildings. Building Code Compliance Document E2, Vol. 4298.

[8] Ismail, S. and Yaacob, Z. (2011) Properties of Laterite Brick Reinforced with Oil Palm Empty Fruit Bunch Fibres. Pertanika Journal of Science and Technology, 19, 33-43.

[9] ASTM (2007) Standard Test Methods for Sampling and Testing Brick and Structural Clay Tile. ASTM International, West Conshohocken, PA.

[10] Reddy, B.V.V., Lal, R. and Rao, K.S.N. (2007) Optimum Soil Grading for the Soil-Cement Blocks. Journal of Materials in Civil Engineering, 19, 139-148.

[11] Pivatto, A., Duarte, D., Marcia, A. and Duarte, D. (2013) Performance Assessment of Makurdi Burnt Bricks. Covenant University Repository, 577-586.

[12] Oushabi, A., Sair, S., Oudrhiri Hassani, F., Abboud, Y., Tanane, O. and El Bouari, A. (2017) The Effect of Alkali Treatment on Mechanical, Morphological and Thermal Properties of Date Palm Fibers (DPFs): Study of the Interface of DPF-Polyurethane Composite. South African Journal of Chemical Engineering, 23, 116-123. https://doi.org/10.1016/j.sajce.2017.04.005

[13] Siregar, J.P., Sapuan, S.M., Zaman, K. and Agency, M.N. (2010) The Effect of Alkali Treatment on the Mechanical Properties of Short Pineapple Leaf Fibre (PALF) Reinforced High Impact Polystyrene (HIPS) Composites. Journal of Food Agriculture and Environment, 8, 1103-1108.

[14] Danso, H., Martinson, D.B., Ali, M. and Williams, J.B. (2015) Effect of Sugarcane Bagasse Fibre on the Strength Properties of Soil Blocks. 1st International Conference on Bio-Based Building Materials, Clermont-Ferrand, 22-24 June 2015.

[15] Devi, L.U., Bhagawan, S.S. and Thomas, S. (1996) Mechanical Properties of Pineapple Leaf Fiber-Reinforced Polyester Composites. Journal of Applied Polymer Science, 64, 1739-1748.

[16] Millogo, Y., Morel, J.C., Aubert, J.E. and Ghavami, K. (2014) Experimental Analysis of Pressed Adobe Blocks Reinforced with Hibiscus cannabinus Fibers. Construction and Building Materials, 52, 71-78.

https://doi.org/10.1016/j.conbuildmat.2013.10.094 